\title{
Desafios do Turismo Pedagógico no Parque Nacional do Vale do Catimbau (PE)
}

\section{Challenges of educational tourism in the Vale do Catimbau National Park (PE, Brazil)}

\author{
Marcelo Henrique de Melo Rocha, Narla Sathler Musse de Oliveira
}

\begin{abstract}
RESUMO: O turismo pedagógico desponta como uma das atividades mais importante dentro do segmento do turismo, por se configurar como uma ferramenta valiosa no processo de ensino aprendizagem. Contudo o desenvolvimento dessa atividade requer não apenas o potencial local, mas uma boa infraestrutura, planejamento prévio e profissionais qualificados, para potencializar os ganhos. Diante disto, o objetivo desta pesquisa é identificar os desafios enfrentados pelos professores e guias de turismo para o desenvolvimento do turismo pedagógico no Parque Nacional do Vale do Catimbau, localizado no estado de Pernambuco. A pesquisa se configura como sendo qualitativa, com coleta de dados por meio de entrevistas remotas com guias e professores, que realizaram atividades no Parque, antes da pandemia. Os resultados obtidos indicaram que entre os desafios para o desenvolvimento do turismo pedagógico na região estão a carência de infraestrutura no parque e no seu entorno, o desconhecimento dos guias sobre a potencialidade pedagógica do parque e a necessidade de melhorias na gestão do parque. A maioria dos entrevistados relataram que o desenvolvimento do turismo pedagógico no Vale do Catimbau tem grande potencial. A grande diversidade de paisagens naturais, sítios arqueológicos, fauna e flora características da caatinga, associados com a riqueza histórica e cultural, faz da região um local propício para o turismo pedagógico.
\end{abstract}

PALAVRAS-CHAVE: Turismo Pedagógico; Sustentabilidade; Vale do Catimbau (PE).

ABSTRACT: Pedagogical tourism emerges as one of the most important activities within the tourism segment, as it is configured as a valuable tool in the teaching-learning process. However, the development of this activity requires not only local potential, but good infrastructure, prior planning and qualified professionals, to maximize gains. Given this, the objective of this research is to identify the challenges faced by teachers and tourism guides for the development of educational tourism in the Vale do Catimbau National Park, located in Pernambuco State. The research is characterized as being qualitative, with data collection through remote interviews with guides and teachers, who carried out activities in the Park, before the pandemic. The results obtained indicated that among the challenges for the development of educational tourism in the region are the lack of infrastructure in the park and its surroundings, the lack of knowledge of guides about the park's educational potential and the need for improvements in park management. Most interviewees reported that the development of educational tourism in the Catimbau Valley has great potential. The great diversity of natural landscapes, archaeological sites, fauna and flora characteristic of the caatinga, associated with the historical and cultural richness, makes the region a favourable location for educational tourism.

KEYWORDS: Educational Tourism; Sustainability, Vale do Catimbau (PE). 


\section{Introdução}

Apesar do intenso processo de devastação vivenciado nas últimas décadas, a caatinga é considerada um ecossistema com uma expressiva biodiversidade abrigando vários espécimes vegetais e animais endêmicas, o que faz deste ecossistema um local procurado por muitos visitantes, que anseiam em conhecer e apreciar as belezas naturais deste domínio morfoclimático brasileiro.

Um destes locais é o Parque Nacional do Vale do Catimbau - PNVC, que foi criado pelo Decreto de 13 de dezembro de 2002 (BRASIL, 2002). O parque está localizado a cerca de $290 \mathrm{~km}$ da Capital Recife/PE, em uma área de aproximadamente 62.300 hectares na Microrregião do Sertão do Moxotó. O objetivo de criação do parque foi para "preservar os ecossistemas naturais existentes, possibilitando a realização de pesquisas científicas e o desenvolvimento de atividades de educação ambiental e turismo ecológico" (BRASIL, 2002).

Além de possuir uma beleza cênica exuberante, o Vale do Catimbau tem um valor histórico inestimável, tendo em vista que o Parque é considerado o segundo maior sítio arqueológico brasileiro, sendo superado apenas pelo Parque Nacional da Serra da Capivara, localizado no Piauí (MARTIN, 2005).

O grande potencial natural e histórico da região atrai anualmente muitos visitantes, entre eles diversos grupos escolares, no chamado turismo pedagógico. A visitação em unidades de conservação é uma estratégia essencial para aproximar a sociedade da natureza e despertar a conscientização da importância da conservação de ambientes naturais, possibilitando uma maior compreensão da problemática ambiental nos processos de aprendizagem, por meio do questionamento e sensibilização (BRASIL, 2006).

Neste sentido, Camargo e Coelho (2021, p. 77), alertam que "embora o turismo venha ganhando destaque em todo território nacional e tenha o potencial de ser fonte de geração de grande parte de nossa riqueza, o tema ainda é pouco difundido nos livros pedagógicos e nas salas de aulas". Sendo assim, torna-se necessário realizar pesquisas e desenvolver estratégias para que as instituições escolares comecem a dar mais atenção às possibilidades educacionais para esta modalidade de turismo.

Para Milan (2007, p. 26), o chamado turismo pedagógico "apresenta-se como uma das recentes modalidades do mercado turístico relacionada às viagens de estudo. Entretanto exibe em seu aspecto conceitual uma série de confusões de ordem semântica e metodológica". Sendo assim, adotaremos, neste texto, o termo turismo pedagógico para as atividades extraclasse ou aulas de campo que envolvem a convivência com o meio natural em uma abordagem interdisciplinar.

Desta forma, como afirma Beni (2004), o turismo pedagógico ou educacional apresenta-se como uma ferramenta oportuna para proporcionar ao sujeito o conhecimento, a vivência, a sensibilização, a convivência, o respeito, o aprendizado e o lazer. De acordo com Ansarah (2001), esta prática tem como objetivo proporcionar ao aluno/turista 0 contato com a natureza promovendo, a partir disso, 0 desenvolvimento de valores construtivos frente às fragilidades socioculturais e ambientais.

Sabemos que uma atividade de campo com foco pedagógico, quando bem executada, é capaz de promover uma aprendizagem mais significativa, um momento único e inesquecível de aprendizado, por meio da interação com o meio, onde os conteúdos podem ser trabalhados de maneira interativa e instantânea. Por isso que 
as aulas de campo e visitas técnicas estão cada vez mais presentes no currículo das instituições educacionais, como ferramentas facilitadoras da aprendizagem.

A nova Base Nacional Comum Curricular - BNCC (BRASIL, 2018, p. 321), aponta a necessidade de os estudantes terem "um novo olhar sobre o mundo que os cercam, como também façam escolhas e intervenções conscientes e pautadas nos princípios da sustentabilidade e do bem comum". Para tanto, é necessário que os alunos possam vivenciar o mundo de forma mais natural, realizando atividades de campo, visitando espaços naturais, onde eles possam vivenciar na prática as relações entre o ser humano e a natureza, com possibilidades concretas de fazer boas escolhas para si e para seu entorno vivencial.

O turismo pedagógico configura-se como possibilidade de os alunos vivenciarem o mundo natural, em uma abordagem interdisciplinar, onde um roteiro pode ser trabalhado a partir do diálogo entre diferentes campos de conhecimento, proporcionando aos participantes uma maior amplitude do objeto de estudo, vivenciando e praticando os aspectos teóricos vistos em sala de aula (MILAN, 2007).

Além disso, o turismo pedagógico, quando bem estruturado, pode ser uma valiosa ferramenta para a educação ambiental, tendo em vista que os alunos entram em contato com o ambiente natural, com a comunidade local, possibilitando uma maior integração com os atrativos turísticos visitados, assumindo um papel ativo no processo de construção da consciência ambiental (PERINOTTO, 2008).

Para Beni (2004) o turismo pedagógico é uma prática antiga, que foi adotada no Brasil por algumas escolas de elite, reproduzido de colégios e universidades europeias e norte-americanas, que organizavam atividades externas para seus alunos, que denominavam de viagens culturais. Estas atividades eram coordenadas pelos professores que levavam os alunos a pontos turísticos ou locais com algum interesse pedagógico que pudesse possibilitá-los a fazerem reflexões sobre diferentes temas e assim, proporcionava-os uma melhor formação educacional.

O grande desafio do turismo pedagógico na atualidade, é que parte das instituições de ensino inserem suas aulas práticas como atividade exclusivamente recreativa, sem um planejamento adequado e participativo. Sendo assim, uma excursão ou uma visita técnica, acaba sendo vista apenas como um passeio pelos alunos e professores, com intuito apenas de propiciar o lazer.

Neste caso os alunos entendem essas atividades, como um momento de folga e diversão e não atribuem importância à atividade, em seu processo formativo. Neste sentido, Perinotto (2008, p.101) afirma que o turismo pedagógico é no geral, "uma prática prazerosa que dificilmente é recusada pelos estudantes; pelo contrário, estes muito apreciam participar de uma viagem ou de um passeio nos arredores da escola, pela cidade ou de uma excursão pela região rural". Cabe aos professores tornar a prática uma oportunidade para a produção de conhecimentos.

E um dos locais onde ocorre o turismo pedagógico é o Parque Nacional do Vale do Catimbau/PE, que tem recebido, ao longo do tempo, um expressivo número de visitantes, principalmente ligados a escolas de ensino fundamental e médio, acompanhados de seus professores, para visitar o parque e suas inúmeras atrações paisagísticas, históricas e culturais. Muitas vezes, estas visitas se configuram somente como passeios para os alunos, não sendo explorados, pelos professores e/ou guias de turismo, as potencialidades pedagógicas que o ambiente do parque possibilita devido a inúmeros fatores. 
Diante disto, o objetivo desta pesquisa é identificar os desafios enfrentados pelos professores e guias de turismo para o desenvolvimento do turismo pedagógico no Parque Nacional do Vale do Catimbau/PE.

O turismo pedagógico em áreas naturais é uma das atividades mais importantes dentro do segmento do turismo, não só por propiciar o conhecimento de novos lugares, mas, sobretudo por ser uma ferramenta valiosa para as atividades de educação e sensibilização ambiental, pois o contato mais íntimo com o meio natural permite ao visitante descobrir novas sensações e percepções de um meio diferente do seu habitual, na maioria das vezes limitados a sala de aula, apresentando ao aluno/visitante um mundo de referências reais palpáveis (PERINOTTO, 2008; CAMARGO; COELHO, 2021).

Antes mesmo da criação do PNVC, em 2002, a demanda turística da região já vivenciava um grande crescimento, mesmo sem apresentar uma infraestrutura adequada para receber os visitantes. O turismo passou a ser uma atividade econômica para a comunidade local, promovendo transformações naturais e sociais na região (SIQUEIRA, 2006; SILVA; PIRES, 2016).

Impulsionados pela indústria do turismo, no mesmo ano da criação do parque, um grupo de moradores do Distrito de Catimbau criou a Associação dos Guias de Turismo do Catimbau - AGTURC. A iniciativa contou com o apoio do Instituto Brasileiro de Meio Ambiente e Recursos Naturais Renováveis - IBAMA e o Serviço Brasileiro de Apoio às Micro e Pequenas Empresas - SEBRAE, que também foram responsáveis pelo treinamento dos guias (MARTINS, 2019).

De acordo com Silva e Maia (2008, p. 213), as atividades turísticas desenvolvidas no PNVC são "em geral, praticadas durante o dia, dentre as quais se destacam: a caminhada, a observação da paisagem/ flora e a fotografia amadora, além de visitas com caráter pedagógico de escolas de cidades próximas e da capital, bem como de universidades". O ambiente do parque é propício para o desenvolvimento de várias atividades pedagógicas com amplas possibilidades de um diálogo interdisciplinar, favorecendo a formação escolar dos alunos (GOMES; RODAL; MELO, 2006; FARIAS, 2009; SOUZA, 2016).

Pertencentes à categoria de proteção integral, os parques nacionais têm como objetivo, dentre outros, a proteção de ecossistemas, a pesquisa científica, a educação e a interpretação ambiental, além de atividades de recreação em contato com a natureza (SILVA; MAIA, 2008). Contudo, a falta de planejamento, o baixo investimento e a pouca infraestrutura para receber turistas, principalmente grandes grupos de alunos, tem trazido uma série de dificuldades para o desenvolvimento do turismo pedagógico sustentável na região.

Em Unidades de Conservação, as trilhas muitas vezes, estão localizadas em áreas com vegetação frágil e, à medida que a sua intensidade de uso aumenta, os impactos são constatados (COTES; ERLER; MIELKE, 2021). Além disso, segundo Costa (2002), a criação de Unidades de Conservação (UC's) tem sido uma prática bastante utilizada em nível mundial para a proteção de ambientes naturais de relevante interesse quanto à biodiversidade e geodiversidade, com atributos peculiares da fauna, da flora, e com a beleza paisagística como recurso turístico.

A atividade turística é de vital importância para as comunidades do entorno e para $\circ$ desenvolvimento do município, porém é necessário atentar-se para 0 planejamento e gestão destas localidades para que questões de proteção ambiental e a participação da comunidade não sejam negligenciadas. A participação da 
comunidade no planejamento da atividade turística pode favorecer a conservação das paisagens e delimitar o uso sustentável do espaço destinado ao turismo (MOREIRA et. al. 2021).

\section{Aspectos metodológicos}

A pesquisa se qualifica como sendo qualitativa, desenvolvida a partir da análise dos depoimentos de professores e guias de turismo que desenvolveram trabalhos com grupos escolares na região, antes da pandemia do Covid-19, uma vez que, a maioria das instituições de ensino, encontra-se até o primeiro semestre de 2021, em trabalho remoto, sem atividades de campo.

A pesquisa iniciou com o levantamento bibliográfico sobre o turismo pedagógico e dados sobre a região do Vale do Catimbau/PE. Posteriormente foram realizadas entrevistas com cinco professores e cinco guias de turismo que atuam na região, indicadas através da AGTURC e que realizavam atividades de campo com grupos de alunos de diferentes escolas antes da pandemia e se disponibilizaram a participar da pesquisa.

Todos os guias, participantes da pesquisa residem em Buique-PE, cidade mais próxima do parque. E os professores são residentes na cidade do Recife, de onde partem a maioria dos grupos que visitam o parque.

As entrevistas aconteceram remotamente por meio do aplicativo WhatsApp. A opção foi pelas entrevistas semiestruturadas onde, segundo Dencker (2000), os entrevistados possuem total liberdade para expressar a sua opinião. A pergunta norteadora inicial foi: "quais os maiores desafios que você encontra para o desenvolvimento do turismo pedagógico no Parque Nacional Vale do Catimbau/PE?". As respostas foram dadas por mensagens de voz, pelo aplicativo. Ao longo da entrevista, de acordo com as respostas, outras perguntas foram surgindo, orientadas por questões que eram levantadas pelos entrevistados. Posteriormente foi realizada a transcrição das respostas para posterior análise.

$\mathrm{Na}$ análise de dados optou-se por preservar o nome dos entrevistados, uma vez que não se trabalhou com análise de discurso e sim com a interpretação das falas relacionadas a pontos comuns entre eles, como por exemplo a opinião acerca de infraestrutura geral do Parque e do seu entorno. Ressalta-se que todos os participantes estavam de acordo com o termo de consentimento livre e esclarecido.

\section{Aspectos fisiográficos do Parque Nacional do Vale do Catimbau/PE}

O Parque Nacional do Vale do Catimbau/PE ocupa uma área de aproximadamente 62.300 hectares, abrangendo os municípios de: Buíque, Ibimirim, Sertânia e Tupanatinga, na Microrregião do Sertão do Moxotó, zona de transição entre o agreste e o sertão de Pernambuco (Figura 1).

Do ponto de vista climático a maior parte da região está inserida no semiárido pernambucano, que segundo Koppen foi classificado como Bshw', quente e seco com chuvas amenas e temperatura média de $24^{\circ} \mathrm{C}$, embora seja possível encontrar no parque áreas com altitudes próximas aos $900 \mathrm{~m}$, que condiciona temperaturas mais amenas e índices pluviométricos que podem ultrapassar $1000 \mathrm{~mm}$ anuais. Porém, em determinadas épocas do ano, as temperaturas podem alcançar 36ํㅜ (SOUZA, 2016; MARTINS, 2019). 


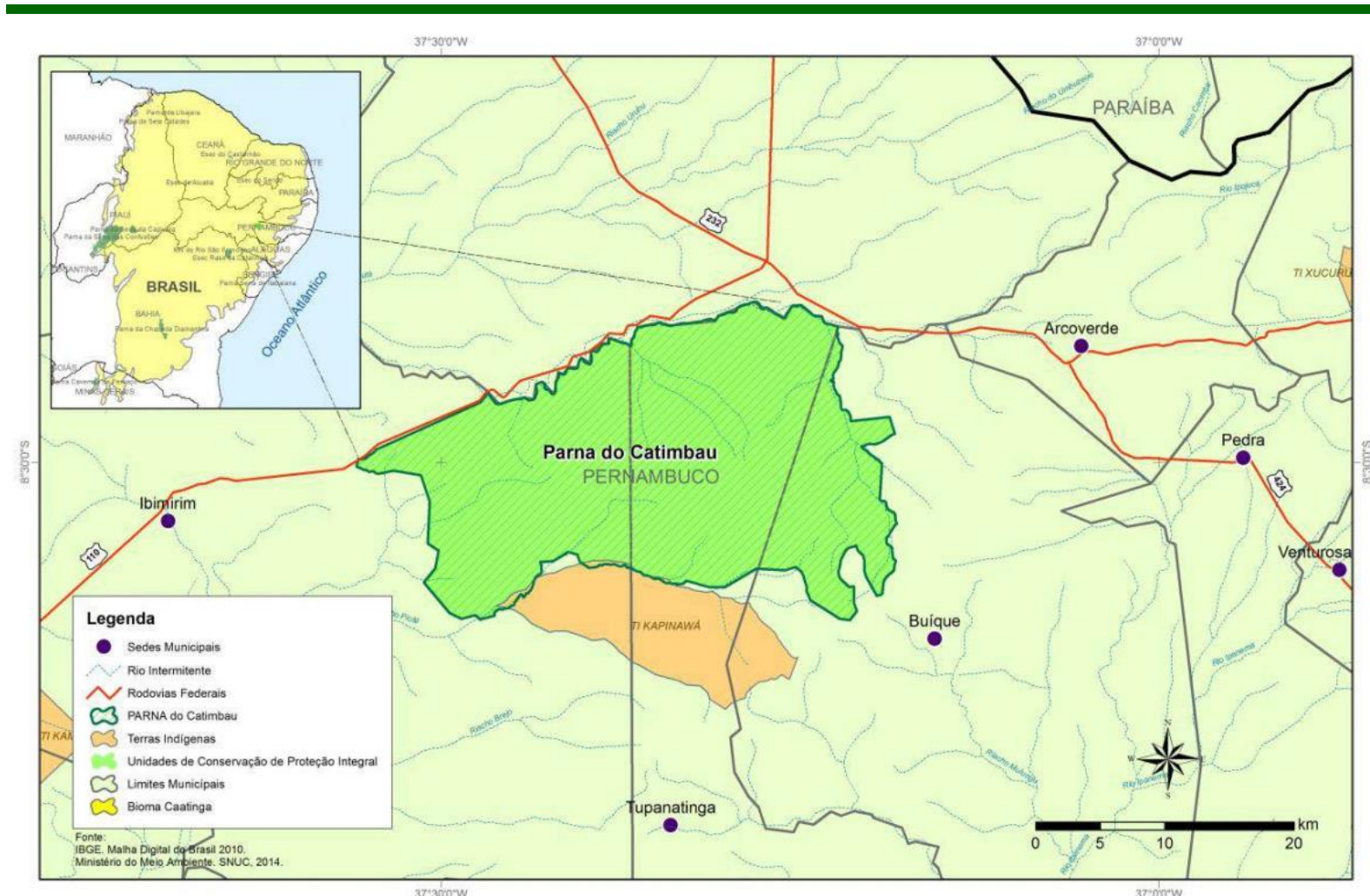

Figura 1: Mapa de localização do Vale do Catimbau, Estado de Pernambuco, Brasil.

Figure 1: Location map of the Catimbau Valley, State of Pernambuco, Brazil

Fonte: Freire et. al. (2015).

Source: Freire et. al. (2015).

A região integra o domínio morfoclimático da caatinga com predomínio de espécies arbóreo-arbustiva, espécies caducifólias e subcaducifólia, apresentando um elevado grau de endemismo. Além disto, é possível observar espécies da caatinga do cristalino e caatinga de áreas sedimentares (GOMES; RODAL; MELO, 2006). Nas regiões mais altas, onde o clima é mais úmido, aparecem matas mais densas, com aspectos mais arbóreos. Além disso, em virtude das variações geomorfológicas e pedológicas, aparecem na região espécies da flora do cerrado, mata atlântica e de campos rupestres (SOUZA, 2016; FARIAS, 2009).

Em relação à fauna da região do Catimbau, são encontradas inúmeras espécies de pássaros como: gavião, carcará, canário do mato, asa branca, além de inúmeros répteis como o lagarto-das-rochas, cascavéis, além de roedores como: mocó e preá, lobo-guará e pequenos felinos (FARIAS, 2009; MARTINS, 2019).

Em relação aos aspectos geológicos e geomorfológicos, encontramos na região quatro Domínios: Depressão do Baixo Rio São Francisco, o Planalto da Borborema, e os dois últimos de maior destaque, a depressão Sertaneja e o Planalto Sedimentar da Bacia do Jatobá (FERREIRA et al., 2014; SOUZA, 2016).

O planalto da Borborema é constituído por formações planálticas, pertencentes ao embasamento cristalino de idade Pré-cambriana, bastante desgastados pela ação erosiva, com altitudes que podem se aproximar dos 1000m (CAVALCANTI, 2013; SOUZA, 2016). As depressões do São Francisco e Sertaneja são encontradas, entre o Planalto da Borborema e o Planalto Sedimentar da Bacia do Jatobá, resultante de uma pediplanação intensa onde frequentemente são encontrados morros testemunhos, inselbergues (CAVALCANTI, 2013; FREIRE, 2015). 
O Planalto Sedimentar da Bacia do Jatobá se apresenta com relevos tabulares de topo suave, com rochas areníticas de diversas granulometrias, intercaladas, formando vales abertos e encostas abruptas, exibindo uma grande diversidade de macro e microformas (Figura 2).

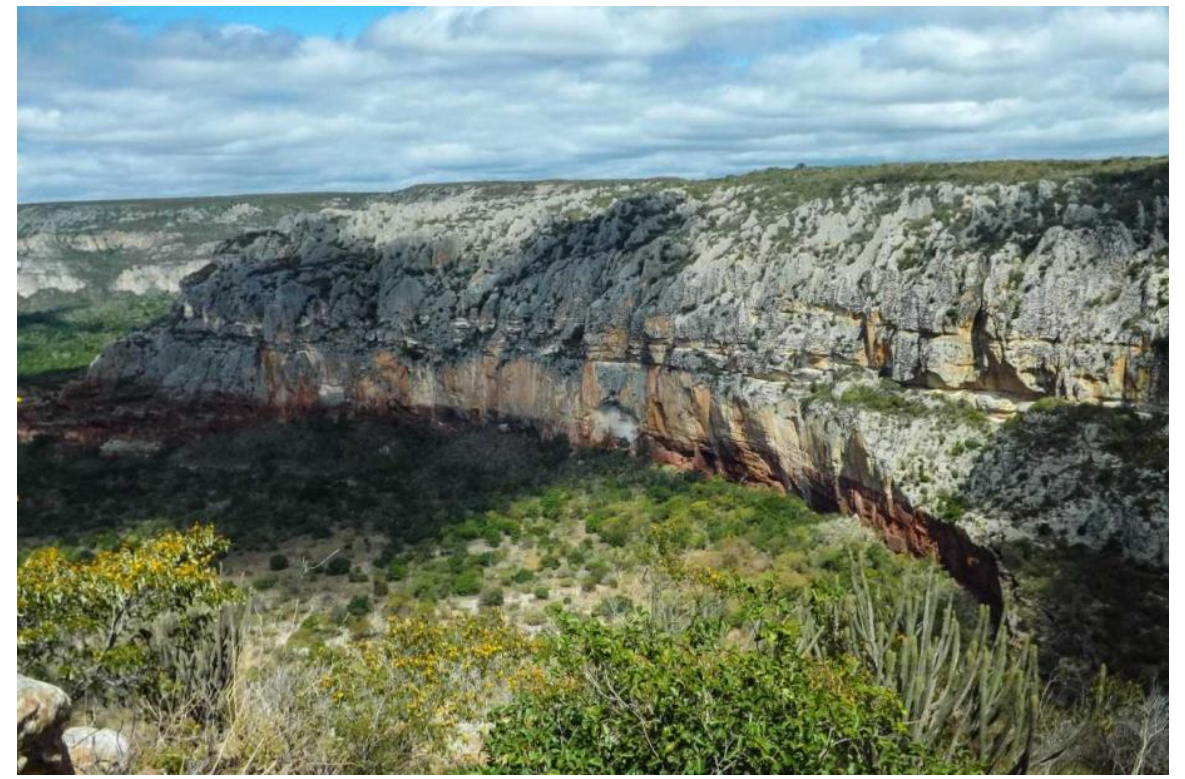

Figura 2: Mirante da trilha do chapadão, Vale do Catimbau, estado de Pernambuco, Brasil. Figure 2: Viewpoint of the Chapadão Trail, Catimbau Valley, State of Pernambuco, Brazil

Fonte: Acervo autores (2019).

Source: Collection authors (2019).

Segundo Cavalcanti (2013), o relevo e formação das paisagens do Vale do Catimbau/PE, são oriundos da ação dos agentes modeladores do relevo, principalmente a água das chuvas e das drenagens, associado aos processos de gravidade e do intemperismo biológico que dão origem ao relevo peculiar encontrados no parque.

\section{Resultados e Discussões}

As atividades de turismo pedagógico desenvolvidas no PNVC são realizadas durante o dia, em trilhas, realizadas a pé, com paradas em pontos onde se pode observar a caatinga, as formas de relevo, os tipos de rochas, a fauna, aspectos climáticos, alterações na paisagem, entre outras características. O ponto de origem das atividades é no vilarejo rural de Catimbau, que fica a $12 \mathrm{~km}$ da cidade de Buíque/PE, que fica bem próximo ao parque e é, onde se localiza a associação dos guias.

O acesso só pode ser realizado na companhia dos guias credenciados na associação - AGTURC. Eles sabem quais são os melhores caminhos a seguir, uma vez que o parque conta com aproximadamente 30 trilhas (informação verbal dos guias entrevistados). Além disto, eles também orientam sobre os pontos a serem visitados e informam qual o tempo de cada uma das trilhas. Os guias foram unânimes ao afirmar a importância de se ter a presença do guia credenciado nas atividades dentro do parque.

Ressaltamos que não há mapas das trilhas que possam ser fornecidas aos visitantes, daí, a importância da presença dos guias durante a atividade. Uma 
pesquisa realizada por Martins (2019, p.297) com os guias da região apontaram que "os guias da associação detêm conhecimento considerável sobre aspectos físicos e institucionais do Parque Nacional do Catimbau, bem como sobre a fauna local".

Sendo assim, os professores entrevistados apontam, como um dos desafios ao desenvolvimento do turismo pedagógico na área, o número pequeno de guias para dar vazão a grupos maiores de visitantes. Como o PNVC recebe visitas, tanto de grupos escolares, como de turistas não escolares, por vezes, há falta de guias para atividades com um tempo maior de duração.

Um dos professores alerta que, em algumas épocas do ano, os guias só podem fazer o guiamento na parte da manhã ou tarde, não tendo disponibilidade para guiamentos mais longos. As visitas só ocorrem com agendamentos realizados com antecedência, junto a associação.

Outro desafio refere-se à pouca sinalização e de informações sobre o parque, desde a chegada à cidade de Buíque/PE, como ao longo de todo o percurso. No deslocamento de um atrativo para o outro existem poucas placas de sinalização. Além do mais, há carência de placas educativas com informações gerais sobre o atrativo turístico e com orientações para a visitação. O ideal seria a presença de placas com dados sobre a idade e identificação das rochas, os processos de formação dos relevos e outros dados referentes a cada ponto visitado.

O roteiro de paradas e o tipo de observações é definido pelos professores e depende do grau de escolaridade dos participantes, assim como a escolha da trilha. De acordo com um dos professores entrevistados "se é aluno mais novo, tipo $6^{\circ}$ e $7^{\circ}$ anos, geralmente fazemos trilhas mais leves, de uma hora e meia a duas horas (ida e volta). Se for de ensino médio, fazemos de duas a três horas, em trilhas de até $5 \mathrm{~km}$ ".

Além disto é possível visitar inúmeros sítios arqueológicos com belas e representativas pinturas rupestres (Figura 3), em trilhas de baixo a médio grau de dificuldade.

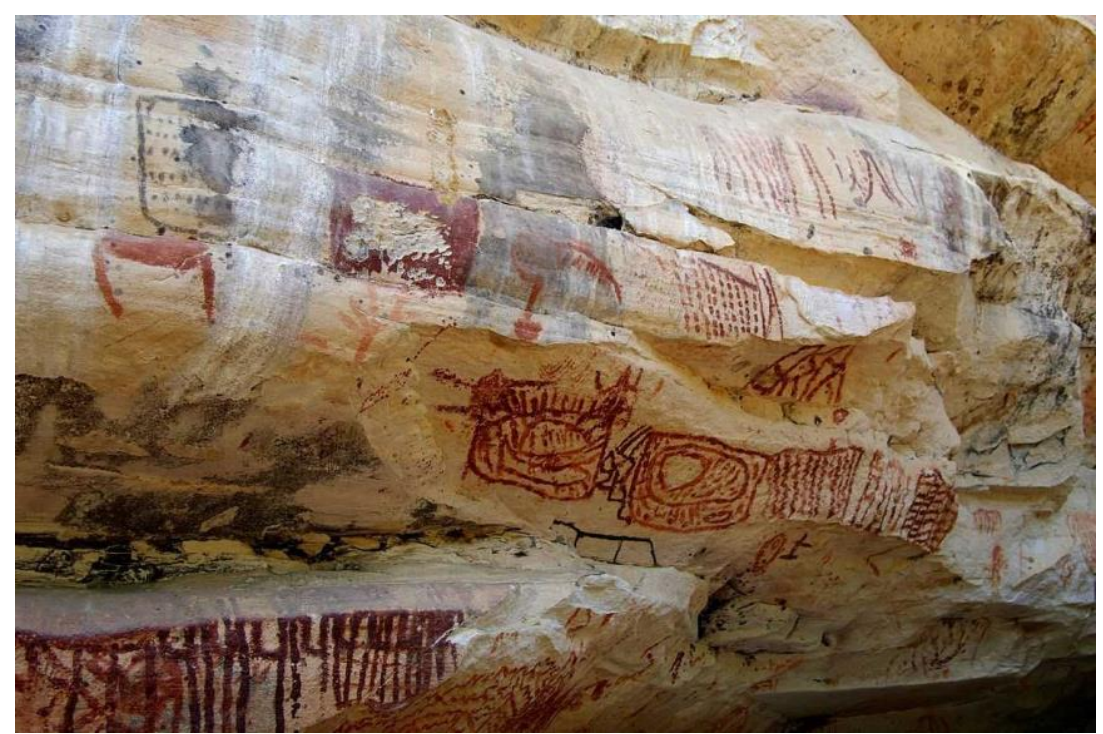

Figura 3: Imagem do Sítio arqueológico de Alcobaça, Parque Nacional Catimbau, com representações de zoomorfos, antropomorfos e grafismos puros.

Figure 3: Image of the archaeological site Alcobaça, Parque Nacional Catimbau, with representations of zoomorphs, anthropomorphs and pure graphics.

Fonte: Acervo autores (2019).

Source: Collection authors (2019). 
De acordo com Cavalcanti (2013, p. 113), no parque é possível observar "pinturas rupestres representativas da Tradição Agreste, um estilo marcado por grafismos puros e representação de antropomorfos, fitomorfos e zoomorfos". Porém, a maioria dos sítios arqueológicos não tem placas de sinalização e nem informações sobre as características das representações.

As pinturas rupestres apresentam grande potencial educativo uma vez que mostram características do espaço geográfico que foi alterado ao longo de milhares de anos por ações naturais e antrópicas. As pinturas evidenciam a presença de uma população de ceramistas e agricultores que utilizavam estes espaços como abrigo e como cemitério (SIQUEIRA, 2006).

Outro fator importante na definição do tempo e das trilhas a serem realizadas, refere-se aos aspectos climáticos. Os professores alertam que, em alguns períodos do ano, as temperaturas são muito altas, o que impossibilita a permanência no parque nos horários de maior incidência solar, como aquelas entre 11:00 e 14:00 horas. Não existem pontos de apoio ao longo das trilhas, onde se pudesse fazer paradas mais longas, no sentido de aguardar o horário de menor insolação. Assim, é necessário organizar as trilhas de forma a ir e voltar em horário compatível com as temperaturas mais amenas, principalmente quando são alunos mais jovens.

Ainda relacionados aos desafios enfrentados por guias e professores para 0 pleno desenvolvimento do turismo pedagógico no Vale do Catimbau refere-se à carência de infraestrutura básica no Parque e seu entorno. Todos os entrevistados, tantos professores quanto os guias locais, apontaram algum tipo de deficiência neste quesito.

E tudo indica que a falta de infraestrutura é um problema comum a outras áreas similares ao Vale do Catimbau, como relatou Serrano (2000), que a principal dificuldade que as Unidades de Conservação enfrentam no desenvolvimento da atividade turística é a inexistência de uma infraestrutura adequada, tanto física quanto de pessoal, para atender e conduzir os visitantes.

Sete das dez pessoas entrevistadas (5 professores e 2 guias), relataram que há insuficiência no número de leitos, considerando por exemplo, uma atividade com escolas, onde o número de alunos fica entre 30 e 40 pessoas, por turma. Além disto, foi apontado também a baixa qualidade de estrutura e serviço nas pousadas próximas ao Parque, uma vez que existem apenas cinco pousadas na cidade, que rapidamente esgotam a sua capacidade.

Sendo assim, grupos maiores necessitam se hospedar em cidades mais distantes, como Pesqueira (58km de distância) e Arcoverde (24km de distância). Ressalta-se que os professores entrevistados são de Recife/PE, distante $293 \mathrm{~km}$ do parque, o que torna impróprio atividades de somente um dia, ou seja, é necessário pernoitar na região, o que inclui alimentação e outras necessidades. Além disto, esta ausência de leitos acarreta a impossibilidade de se planejar uma atividade no parque de mais de um dia.

Além da hospedagem, há problemas também com as refeições. A maioria das visitações das escolas são realizadas durante os dias de semana e, assim, encontram muitos restaurantes fechados ou com uma capacidade reduzida de atendimento. $\mathrm{Na}$ percepção de um dos guias entrevistados "no geral, os restaurantes se preparam para um movimento maior apenas nos fins de semana, com a chegada de muitos turistas. Assim, muitas vezes tivemos que dividir um grupo da mesma escola, para almoçar em 
dois ou três restaurantes". Este fato representa, na opinião dos professores, um grande contratempo para eles, que necessitam dar assistência a todos os alunos e acabam sobrecarregados no ir e vir de um estabelecimento ao outro.

Ainda sobre a questão da infraestrutura do local, no que se refere a atendimento médico hospitalar, a Vila do Catimbau conta com uma Unidade Básica de Saúde, para atendimentos básicos, contudo os atendimentos de emergência são encaminhados para o hospital Municipal ou Unidade de Pronto atendimento, ambos em Buíque/PE. Segundo um dos guias entrevistados, eles foram capacitados para os primeiros atendimentos em primeiro socorros, mas no geral não costumam conduzir os grupos levando um kit apropriado para atendimentos de emergência.

Outro ponto destacado pelos professores é a dificuldade de locomoção dentro do parque. As estradas para as trilhas são estreitas e na maioria das vezes estão inacessíveis. Apenas uma parte da via principal que leva aos principais atrativos é pavimentada. A chuva ou passagem de carros pipas que ao longo do trajeto derramam água, deixam as estradas sem condições de circulação para ônibus e micro-ônibus, principal meio de transporte utilizado pelo turismo pedagógico, obrigando os grupos a alugarem veículos com tração nas quatro rodas adaptados para o transporte de passageiros. Porém o número de veículos com essas características é pequeno na cidade, sendo necessário, muitas vezes, alugá-los em cidades vizinhas.

Além da falta de infraestrutura local, foi relatado que há por parte dos moradores um grande desconhecimento sobre o potencial histórico, científico e cultural do parque, e isso acaba afetando a preservação do local. De acordo como um dos professores entrevistado afirma "se não há uma sensibilização das comunidades do entorno, sobre a importância daquele lugar, ele continuará esquecido, e o pior, esquecido por quem mais deveria valorizar".

Este fato é corroborado pela pesquisa realizada por Silva e Maia (2008, p. 2016) sobre a percepção dos moradores do Catimbau/PE a respeito da do turismo no parque onde se constatou que "o envolvimento com a atividade se limita aos guias, e a maioria dos moradores se encontra alheia à situação do parque". Como, parte da população, não se sente partícipe do processo de criação do PNVC e ficam inseguros com sua situação, verifica-se situações extremas como a que foi relatado por Silva e Maia (2008, p. 2016) "esse ambiente de incertezas gera medo e contribui com atitudes negativas em relação ao parque, desencadeando ações extremas como a tentativa de destruição de pinturas rupestres por alguns dos proprietários".

A respeito do grau de dificuldade para a realização das trilhas, bem como o aproveitamento pedagógico dos atrativos, a maioria dos entrevistados relataram que na região existe uma grande diversidade de trilhas, com possibilidade de se adequar as características físicas e necessidades pedagógicas do grupo. Há inúmeras possibilidades dos professores, de diferentes áreas de conhecimento, trabalhar com os alunos aspectos variados da região. Os professores foram unânimes em apontar o PNVC como um local perfeito para a realização do turismo pedagógico, levando em consideração suas características físicas, biológicas e culturais.

\section{Considerações finais.}

Levando em consideração o que orienta a Base Nacional Comum Curricular BNCC (BRASIL, 2018, p. 322), sobre a área das Ciências da Natureza, em que o aluno deve vivenciar situações desafiadoras que "estimulem o interesse e a 
curiosidade científica dos alunos e possibilitem definir problemas, levantar, analisar e representar resultados; comunicar conclusões e propor intervenções", consideramos que o turismo pedagógico cumpre esta função com inúmeras possibilidades em todos os campos de conhecimento.

Esta atividade vem se mostrando como um importante instrumento motivador, para a descoberta de um novo olhar mais consciente do mundo, atuando como um grande facilitador de aprendizagem, pois possibilita aos alunos uma aprendizagem mais significativa, a partir da oportunidade de vivenciar de forma prática, temas que geralmente, são abordados apenas dentro de sala de aula.

Os dados da pesquisa revelaram que, tanto os professores quanto os guias acreditam no potencial do turismo pedagógico no Vale do Catimbau. Apesar das dificuldades apontadas, a grande diversidade de elementos e paisagens naturais, associadas com a riqueza histórica e cultural, fazem da região um lugar de muita riqueza para os alunos.

Os entrevistados mostraram-se esperançosos com relação ao futuro do turismo pedagógico no Parque pós-pandemia, "a suspensão das aulas durante o ano letivo 2020/2021, trouxe inúmeras lacunas para os alunos, conteúdos que não foram absorvidos, acredito que as viagens pedagógicas serão um instrumento importante para ajudar a reparar o dano pedagógico deixado pela pandemia", relatou um dos professores entrevistados.

Contudo precisamos destacar que os desafios no Vale do Catimbau ainda são imensos. O turismo surgiu na região de maneira espontânea e descontrolada, e a infraestrutura para atender os visitantes não acompanhou a demanda turística. Os desafios retratados pela pesquisa evidenciam a falta de apoio da iniciativa privada e gestores públicos. Importante ressaltar também o desconhecimento de parte da população, a respeito das riquezas e potencialidades do lugar, corroborando para limitar o desenvolvimento do turismo pedagógico na região.

Um futuro mais promissor para o turismo pedagógico na região do Vale do Catimbau perpassa por um planejamento mais efetivo, que desperte um interesse coletivo, para o desenvolvimento de ações conjuntas entre governos, sociedade civil e setor privado, para o melhor aproveitamento de toda sua potencialidade. Isto já acontece em outras unidades de conservação brasileiras, onde o turismo representa um fator relevante do ponto de vista social, ambiental e econômico para a região onde estão inseridas, o que evidencia as possibilidades de isto também ocorrer no PNVC.

\section{Referências}

ANSARAH, M. G. dos R. Turismo: como aprender, como ensinar. São Paulo: Editora SENAC São Paulo, 2001.

BENI, M.C. Análise Estrutural do Turismo. 10ªed. Atual. São Paulo: Editora SENAC São Paulo, 2004.

BRASIL. Decreto no 9771, de 13 de dezembro de 2002. Cria o Parque Nacional do Catimbau, nos Municípios de Ibirimirim, Tupanatinga e Buíque, no Estado de Pernambuco, e dá outras providências. Disponível em $<$ http://www.planalto.gov.br/ccivil 03/dnn/2002/dnn9771.htm > Acesso em 15 de maio de 2021. 
BRASIL. Decreto no $\mathbf{5 . 7 5 8}$ de 13 de abril de 2006. Institui o Plano Estratégico Nacional de Áreas Protegidas - PNAP, seus princípios, diretrizes, objetivos e estratégias, e dá outras providências. Disponível e: $<$ https://legislacao.presidencia.gov.br/atos/?tipo=DEC\&numero=5758\&ano=2006\&at o=526ATSU50MRpWTb24> Acesso em 15 de maio de 2021.

BRASIL. Ministério da Educação. Base Nacional Comum Curricular. Brasília, 2018. CAMARGO, C. F. de; COELHO, S. C. A. Aspectos da educação e da interpretação ambiental no Ecoturismo no Brasil. Revista Brasileira de Ecoturismo, São Paulo, v. 14, n.1, p.74-83, 2021.

CAVALCANTI, L. C. de S. Da descrição de áreas à teoria dos geossistemas: uma abordagem epistemológica sobre sínteses naturalistas - PE. 2013. 216f. Tese (Doutorado). Universidade Federal de Pernambuco. Recife, 2013.

COSTA, P.C. Unidades de Conservação: matéria-prima do ecoturismo. São Paulo: Editora Aleph, 2002.

COTES, M.; ERLER, D. M.; MIELKE, M. S. Trilhas Interpretativas em áreas de Mata Atlântica: um diagnóstico a partir de fotografias hemisféricas. Revista Brasileira de Ecoturismo, São Paulo, v. 14, n.2, p. 160-177, 2021.

DENCKER, A. F. M. Métodos e técnicas de pesquisa em turismo. São Paulo: Editora Futura, 2000.

FARIAS, G. B. Aves do Parque Nacional do Catimbau, Buique, Pernambuco, Brasil. Atualidades Ornitológicas, v. 1, n. 147, p. 36-39, 2009.

FERREIRA, R. V.; DANTAS, M. E.; SHINZATO, E. Origem das Paisagens. In: TORRES, F. F. M.; PFALTZGRASS, P. A. S. (Org.). Geodiversidade do Estado de Pernambuco. Recife: CPRM, 2014. p. 51-70.

FREIRE, N. C. F. F. et. al. Mapeamento e análise espectro-temporal das unidades de conservação de proteção integral da administração federal no bioma caatinga: Parque Nacional do Catimbau. Relatório Parcial da Pesquisa. Recife, 2015.

GOMES, A. P. de S.; RODAL, M. J. N.; MELO, A. L. de. Florística e fitogeografia da vegetação arbustiva subcaducifólia da Chapada de São José, Buíque, PE, Brasil. Acta Botanica Brasilica [online]. v. 20, n. 1, p. 37-48, 2006.

MARTIN, G. As pinturas rupestres do Sítio Alcobaça, Buíque - PE, no contexto da tradição agreste. Clio Arqueológica. Recife, v. 1, n. 18, p. 27 49, 2005.

MARTINS, C. S. G. Percepções e atitudes dos guias de turismo do Parque Nacional do Catimbau em relação à fauna silvestre. In: SIQUEIRA, F. S. S. et. al. Ecologia e conservação da caatinga: curso de campo 2015. Recife: Ed. UFPE, 2019, p. 284 303.

MILAN, P. L. Viajar para aprender: Turismo Pedagógico na Região dos Campos Gerais - PR. 2007. 125f. Universidade do Vale do Itajaí. Dissertação (Mestrado). Balneário Camboriú, 2007.

MOREIRA, S. A.; SILVA, I. R.; DUTRA, C. K. T.; CUNHA, S.; SANTOS, G. C. dos; SOBRINHO, B. F. N.; BRIDI, G. Rota dos Nativos sob a perspectiva do turismo sustentável: estudo em comunidades de Nísia Floresta (RN). Revista Brasileira de Ecoturismo, São Paulo, v. 14, n. 2, p. 254-281, 2021. 
PERINOTTO, A. R. C. Turismo pedagógico: uma ferramenta para educação ambiental. Caderno Virtual de Turismo, v. 8, n. 1, p.100-103, 2008.

SERRANO, C. A educação pelas pedras: uma introdução. In: SERRANO, C. (Org.). A educação pelas pedras: ecoturismo e educação ambiental. São Paulo: Editora Chronos, 2000, p. 47-84.

SILVA, H.; MAIA, J. B. A. O turismo no Parque Nacional do Catimbau: avaliação dos benefícios da atividade percebidos pelos moradores. Turismo - Visão e Ação, v. 10, n. 2, p.204-220, 2008.

SILVA, J. H. DA; PIRES, M. L. L. S. Associativismo em áreas protegidas: restrições e possibilidades na experiência dos guias de turismo do Catimbau, Pernambuco. Ambiente \& Sociedade [online], v. 19, n. 2, p. 169-186, 2016.

SIQUEIRA, G. R. Avaliação da implementação do Parque Nacional do Catimbau -PE: uma análise do desenvolvimento sustentável na perspectiva do ecoturismo e da comunidade local. 2006. 173f. Universidade Federal de Pernambuco. Dissertação (Mestrado). Recife, 2006.

SOUZA, T. F. Pinturas rupestres e paisagem: um estudo de caso das representações zoomórficas do Vale do Catimbau - PE. 2016. 179f. Universidade Federal de Pernambuco. Dissertação (Mestrado). Recife, 2016.

Marcelo Henrique de Melo Rocha: Universidade Federal de Pernambuco, Recife, PE, Brasil.

E-mail: rochageografia@hotmail.com

Link para o currículo Lattes: http://lattes.cnpq.br/3049363337309865

Narla Sathler Musse de Oliveira: Instituto Federal de Educação, Ciência e Tecnologia do Rio Grande do Norte, Natal, RN, Brasil.

E-mail: narla.musse@ifrn.edu.br

Link para o currículo Lattes: http://lattes.cnpq.br/2477295938118466

Data de submissão: 27 de agosto de 2021

Data de recebimento de correções: 25 de novembro de 2021

Data do aceite: 25 de novembro de 2021

Avaliado anonimamente 